\section{ENTREVISTA COM O PROF. JOÃO DOS REIS SILVA JÚNIOR}

INTERVIEW WITH PROF. JOÃO DOS REIS SILVA JÚNIOR

ENTREVISTA AL PROF. JOÃO DOS REIS SILVA JÚNIOR

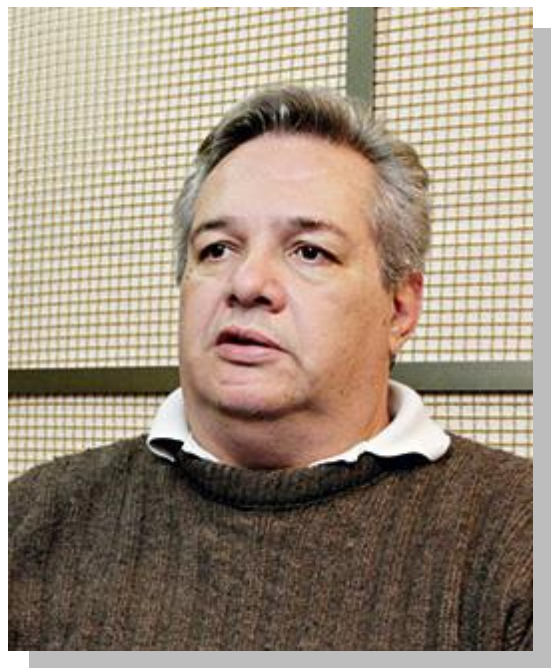

O entrevistado dessa vez na Revista Internacional de Educação Superior é o professor doutor João dos Reis da Silva Júnior. O professor João possui graduação em Escola de Engenharia de São Carlos pela Universidade de São Paulo, concluído em 1982, mestrado em Administração pela Pontifícia Universidade Católica de São Paulo finalizado em 1988 e fez o doutorado em História e Filosofia da Educação pela Pontifícia Universidade Católica de São Paulo em 1992. No Departamento de se Sociologia Política da Universidade Estadual de Campinas, entre os anos de 1999 e 2000, concluí o estágio de Pós-Doutorado. Possui também Pós-doutorado em Economia pela Universidade de São Paulo (USP) e pela University of London. É Livre-Docente em Educação pela também pela Universidade de São Paulo (USP), e é professor titular da Universidade Federal de São Carlos (UFSCar), sendo coordenador adjunto do projeto de pesquisa da Rede Universitas/Br "Políticas, gestão e direito à educação superior: novos modos de regulação e tendências em construção". Pesquisador convidado da Mercer University (GA-US) e Professor Visitante na condição de Full Professor na Arizona State University entre 2014 a 2015, onde mantém pesquisa em andamento com Daniel Schugurenscky. Tem experiência na área de Educação, com ênfase em educação e trabalho, reforma do estado, educação superior brasileira, politica educacional e internacionalização da educação superior brasileira no contexto das relações entre Brasil e Estados Unidos da América.

Submetida em: 04/04/2018 - Aceita em: 02/06/2018 - Publicada em: 31/07/2018.

Fonte da foto: http://www.jornal.uem.br/2011/index.php/edicoes-2012/93-jornal-107-outubro2012/855entrevista 


\section{A - A new American university/World Class University e a universidade brasileira}

Considerando que o paradigma da "new American University" é muito caro, uma vez que até dentro dos Estados Unidos, ele não é generalizado, que precisa ser feito pelo Estado brasileiro e por algumas universidades brasileiras que podem ter a pretensão de aspirar a se tornar uma "world class university" para contribuir para a melhoria da qualidade da educação superior no país e para o desenvolvimento do país, retendo nossos melhores cérebros e atraindo outros do exterior, e não simplesmente exportando gratuitamente esses melhores cérebros para os países já ricos?

João dos Reis da Silva Júnior: Nos Estados Unidos, assim como no Brasil o sistema de educação superior é muito heterogêneo e diferenciado. Contudo o que está em jogo é toda forma de educação superior no mundo em razão da financeirização da economia mundial, da nova geopolítica global e da falência, onde já houve, do Estado de Bem-Estar Social e as respectivas instituições de educação superior correspondentes. O regime de predominância financeira produz um sistema monetário mundial que, em consequência faz emergir uma economia mundializada. A principal característica desse regime, como diz Claude Serfati consiste na "vertigem de Fazer Dinheiro". Dinheiro produzindo dinheiro, epifanicamente, sem a mediação do trabalho. Na expressão de Marx em vez de uma economia baseada na equação D-M-D-D', teríamos tão somente e de forma abstrata, mas que põe as relações e políticas em movimento, apenas D'-D, com D'>D. Ou seja, a simples propriedade do dinheiro possibilitaria na forma de juros a produção de mais dinheiro. Isso exigiu o novo ordenamento jurídico do país e impôs a Reforma do aparelho do Estado e da forma como ela especificamente fora feita sob a coordenação de Bresser-Pereira e orientação dos intelectuais da Escola de Chicago. Nos Estados Unidos não houve a necessidade da Reforma do Aparelho do Estado, posto que a economia americana sempre fora privatizada.

Em matéria da revista Ensino Superior da UNICAMP, de Daniela Klebis, sobre as mudanças na universidade brasileira, Luiz Bevilacqua, ex-coordenador da estruturação da Universidade Federal do ABC, argumentou que o modelo brasileiro estava atrasado e defendeu o modelo da New American University. Com base em dois artigos de Terry Eagleton, da Universidade de Lancaster UK, muito crítico ao movimento de convergência para a World Class University, e, em artigo de Nicholas Dirks, defensor do renascimento da universidade de pesquisa, mas a aplicada, argumenta ele:

Dirks, de Berkeley, critica também a redução de financiamento do governo e a crença crescente de que a pesquisa (a não "aplicada") não pode mais ser a missão primária das grandes universidades. Em seu artigo, defende as ações de reformulação tomadas por Michael Crow, president da Universidade do Estado do Arizona (ASU) desde 2002. Segundo Dirks, o modelo milita em favor da ideia de que a pesquisa deve ser mantida como principal característica da Universidade, que 'não pode ser dispensada na estrada para educação de massa'. Assim como a UFABC, no Brasil, a implantação de um novo modelo acadêmico na ASU foi facilitada pela sua atuação discreta - e desacreditada - entre as universidades mais renomadas dos Estados Unidos. Em

\begin{tabular}{l|l|l|l|l|l|} 
(C) Rev. Inter. Educ. Sup. & Campinas, SP & v.4 & n.3 & p.746-753 & set./dez. 2018
\end{tabular}


fevereiro de 2015, Crow publicou o livro Designing the New American University (Concebendo a nova universidade americana), obra na qual descreve o modelo implantado, com maior acessibilidade, representatividade regional e nacional. $\mathrm{O}$ plano acadêmico ASU se assemelha bastante ao projeto brasileiro de Bevilacqua ao estabelecer novos modos de combinar disciplinas, nova organização de colaborações baseada em projetos de solução de problemas, novas relações entre interesses acadêmicos, necessidades de pesquisa e os imperativos do setor privado, além de também simplificar o processo de admissão. A produtividade científica cresceu $250 \%$ em 13 anos. Apesar dos números, suas propostas inovadoras nem sempre são vistas com bons olhos. Dirks fala que, a exemplo da visão de Crow, Berkeley também está se reformulando a partir de um modelo de colaboração interdisciplinar e internacional, que, porém, mantém o ensino da graduação central no projeto. O reitor conta que a ASU foi importante para levantar o debate nos EUA sobre qual caminho o ensino superior deve seguir. "Hoje existe uma competição entre as universidades americanas para estabelecer seus próprios novos modelos de educação superior. E, enquanto o debate segue, é crucial que o nosso compromisso com a pesquisa se mantenha firme", conclui (KLEBIS, 2015, s/p).

Procurando detalhar um pouco mais a questão relevante aqui apresentada. Até há bem pouco tempo, o grande problema do capital consistia em diminuir o gap entre a ciência e a tecnologia e, embora houvesse uma aproximação entre a universidade e a indústria, ocorria, porém, uma considerável demora na solução dos problemas. Os intelectuais das indústrias estavam distantes dos processos de pesquisa e os pesquisadores, ávidos na defesa da autonomia de sua pauta de pesquisa, permaneciam distantes do front industrial e econômico. Contudo, com a falência do regime monopolista de produção e a emergência da predominância financeira, este quadro se altera de forma radical. Ocorre que o ciclo de capital portador de juros, faz dinheiro sem trabalho. Na equação marxista, temos $\mathrm{D}^{\prime}>\mathrm{D}$. $\mathrm{O}$ proprietário do dinheiro investe, empresta e recebe os juros como forma de pagamento desta operação pela mera propriedade privada do dinheiro. Esta operação, além de econômica, é jurídica e impõe as taxas de juros e o tempo de pagamento do que é devido, desconsiderando o que irá ocorrer no processo de produção real de valor e as condições sociais e de vida do trabalhador. É uma aposta com o menor risco e a maior rentabilidade.

Esta operação pode ser feita entre amigos, empresas, grupo de empresas, países e pelos principais agentes institucionais que atuam mundialmente, que são os fundos mutuais, os guias da gestão do sistema monetário mundial, aos quais se subordinam os fundos de pensão e os fundos dos Grupos Predominantemente Industriais (GPI), o que caracteriza um regime de predominância financeira. Quais as consequências disso? Juridicamente, o ciclo financeiro comprime não só o ciclo do capital em funções (as relações sociais de produção), como também as relações sociais em geral, altera a sociabilidade e subjetividade de todo cidadão e exige a produção de valor real em tempo recorde do trabalho vivo. Aí está o verdadeiro problema do capital e a necessidade de fazer desaparecer o gap entre ciência e tecnologia. Neste ponto, a universidade de pesquisa cumpre o papel mais estratégico. Como? Redefinindo a ciência e o conhecimento, conforme a referida necessidade. Por esta via, a racionalidade econômico-financeira interpõe-se nas práticas cotidianas da vida universitária. 
$\mathrm{O}$ que as pesquisas, o trabalho do pesquisador e do professor precisam apresentar é o conhecimento matéria-prima (Raw Material Knowledge"). A epistemologia desse novo tipo de conhecimento traz em seu centro a racionalidade e tem origem nas demandas do capital financeiro que, muitas vezes, o próprio reitor ou presidente da universidade sabe quem é o sujeito da demanda. Aqui toca-se com a mão a mercantilização da educação superior no plano mundial, mas sob a coordenação de países hegemônicos, beste caso, os Estados Unidos.

Você considera que o regime de capitalismo acadêmico, no caso americano, foi demandado apenas pela nova economia (conhecimento como mercadoria) ou foi também fruto da própria atuação proativa da universidade, ou seja, fruto da criatividade científica, proposta de solução de problemas materiais, econômicos, sociais, humanos (saúde, cura de doenças etc) e biológicos?

João dos Reis da Silva Júnior: A mudança de lugar e modelo da educação superior nos Estados Unidos e no Brasil não se deve somente à predominância financeira, embora ela seja o fator estrutural a exigir a mudança em âmbito mundial, tal qual Phillip Altbach defende em sua Teoria da Convergência. Por outro lado, é relevante destacar que os Estados Unidos teriam transformado o estudante em consumidor, ao transferir o financiamento das instituições para os alunos. Ao mesmo tempo, induzia a universidade à mercantilização, processo que teria sido institucionalizado pelo Estado por meio do Federal Student Aid - no Office of the U.S. Department of Education ("Proud and Sponsor the American Minds"). Quanto à iniciativa dos pesquisadores, não há dúvida que as novas demandas, ainda que lhes tira a autonomia de escolha de seu programa de pesquisa, complementam de forma generosa seu salário, além de financiar a educação superior, o que é traço do Estado americano desde sempre.

Que críticas podem ser feitas ao modelo da New American University/World Class University? E ao contrário, que benefícios desse novo modelo podem advir para o país?

João dos Reis da Silva Júnior: Como se pode observar pelo que argumentamos anteriormente, os benefícios para os Estados Unidos consistem em deslocar as instituições de educação superior de um lugar social em que ela exercia função em benefício do bem público para fazer parte das cadeias produtivas locais, nacional e mundiais, sob sua hegemonia. Resta saber se isto é bom para outros países, especificamente para o Brasil.

Quanto às críticas já embrionárias em questões anteriores pode-se argumentar que a universidade está no fio da navalha entre o estatal e o absolutamente privado. Posto que não é interessante deixar de ser estatal, especialmente porque à exceção da The University of Waschington Office of Federal Relations localizada em Washington, D.C., todas as demais são estaduais e sujeitas às constituições de seus estados. Qualquer equívoco legal, especialmente nas pesquisas farmacêuticas, genéticas, e na biologia em geral, que pode, com 
muita probabilidade, incorrer em júri popular não pode ir para Suprema Corte dos Estados Unidos por lei de um país que se organiza segundo uma confederação e não uma federação de estados, como é o caso brasileiro. Esta situação, em face do lugar agora ocupado pela universidade daquele país, agora, presidido pelo empresário de Wall Street do difícil ramo imobiliário, Trump; a resolução de um problema como o referido atenua-se no plano dos estados em que se localizam as instituições.

Com a privatização do conhecimento, produção de formas estreitas de conhecimento, busca de lucros pela universidade; escolha de reitores/presidentes gestores e buscadores de grants, priorização de atendimento dos interesses das corporações, novos valores estão entrando nas universidades, redesenhando os limites entre o público e o privado. Diante desse quadro, os novos intelectuais da universidade são os formadores das novas gerações de líderes e se tornam empreendedores em busca de grants. A nova forma de hegemonia é produto dos próprios intelectuais nas instituições. Diante desse cenário, que precisa ser feito para preservar os valores históricos relevantes das próprias universidades públicas?

João dos Reis da Silva Júnior: Diante deste quadro e dessa institucionalidade é impossível fazer qualquer coisa. Restam os velhos intelectuais que ainda se inspiram em John Salks, inventor da primeira vacina contra a poliomielite em 1952, a Edward R. Murrow, quando indagado sobre quem seria o proprietário da patente da vacina. "Bem, a sociedade, eu diria. Não há patente. Você poderia patentear o sol?".

\section{B - Avaliação das universidades brasileiras e de sua pós-graduação}

Nossas universidades estão sendo avaliadas por indicadores de produtividade relacionados ao desempenho econômico e financeiro, como ocorre nas congêneres americanas, gerando riqueza para o país, registrando patentes no Brasil e contribuindo para a melhoria da qualidade da educação, da competência científica e técnica do pais e da saúde do povo brasileiro?

João dos Reis da Silva Júnior: É importante dizer que esta afirmação não procede. Nossa produção de patentes e a contribuição para o aumento da rentabilidade econômica do Brasil é no mínimo pífia comparada aos outros países. Por que razão isso acontece? Em razão da servidão voluntária do Brasil para com os Estados Unidos. Por outro lado, ao analisarmos o setor público e todo esforço para o aumento do desempenho da indústria brasileira e da produtividade da economia do país, esbarra-se na âncora monetária colocada pelo Fundo Monetário Internacional em 1982.

Neste ponto, é fundamental tratarmos, ainda que de forma breve, da construção histórica da falência industrial e da ausência de aumento da produtividade da economia, apesar de toda mudança havida na educação superior brasileira em seu conjunto. 
Segundo Bresser-Pereira, em seguida à estabilização produzida pelo Plano Real em 1994/1995, a política econômica exigia um processo que se pautava especialmente pela diretriz "crescer com poupança externa", o que, segundo ele, seria crescer "com déficit em conta corrente, já que poupança externa é déficit em conta corrente. A única preocupação era manter a baixa inflação por meio de uma âncora, que poderia ser ou o câmbio fixo ou de câmbio flutuante acompanhado de sistema de metas de inflação" (s/p). Isso implicaria o controle rígido do déficit público "para que a capacidade do Estado de pagar a sua dívida pública interna e externa não ficasse ameaçada" ( $\mathrm{s} / \mathrm{p}$; grifo nosso). O que consiste no resultado desastroso para o crescimento da economia brasileira e a continuidade da vulnerabilidade econômica do país. É interessante notar o que se grifou nesta citação do autor. O que é central é manter a capacidade de pagamento da dívida pública externa e interna, mais especificamente, manter a dívida e pagar os juros, que são o lucro dos nossos credores internacionais. Isto é, os bancos, já que o modelo implantado pelo FMI em 1982, tem orientado a própria produção acadêmica sobre o problema do país. Isto está posto desde meados da década da primeira metade de 1980 por meio de processo de construção das condições históricas da institucionalização da ruptura com o neodesenvolvimentismo, que se faz com a reforma administrativa do Estado em 1995.

Considera que os critérios utilizados pela CAPES para avaliar a qualidade dos programas de pós-graduação avaliam efetivamente o impacto dos programas na educação brasileira, no desenvolvimento econômico, social e cultural do país e no bem-estar do povo brasileiro?

João dos Reis da Silva Júnior: Pelo que já se disse aqui, a Capes tornou-se uma Agência Reguladora do Sistema Nacional de Pós-Graduação no país. Ao mesmo tempo que financia, ela avalia os programas e impõe para os programas de pós-graduação tornarem-se o polo irradiador das metamorfoses da educação superior brasileira seguindo o modelo da $\mathrm{New}$ American University. Contudo, servil e subordinada, produzindo uma divisão internacional do trabalho acadêmico e científico. Desenvolvo com detalhes tal questão no meu livro The New Brazilian University: a busca de resultados comercializáveis - para quem? Tudo que produzimos cientificamente de bom no país não impacta a economia brasileira, pois o fundo público brasileiro é destinado ao pagamento da dívida pública. Atualmente o montante desse pagamento chega próximo de 50\% do orçamento anual do país. Que ganha são os prepostos do capital financeiro. Assim, o que produzimos cientificamente e as patentes fogem do país com destino dos Estados Unidos e da Europa. Quando o cientista é bom, ele se vai também, a exemplo do excelente Miguel Nicholelis.

Você avalia que os critérios utilizados pela CAPES para avaliar a qualidade dos programas de pós-graduação tem preservado a autonomia da universidade brasileira no exercício qualificado de suas três funções tradicionais? 
João dos Reis da Silva Júnior: penso ter dado conta dessa pergunta na questão anterior. Considera que os programas de pós-graduação em educação que, segundo o critério CAPES (notas 6 e 7), têm padrão internacional, têm contribuído efetivamente a melhoria da qualidade da formação de seus pós-graduandos em educação e da educação do país? Também a educação caminha na mesma direção com raríssimas exceções, o Programa Escola sem Partido e a Reforma do Ensino Médio que será feita pela Fundação Lemann mostram não somente a difusão do conhecimento matéria prima, mas também a formação do novo cidadão. Um cidadão que se torna um AGENTE ECONÔMICO.

\section{C - Proposta para preservação das características históricas essenciais da universidade}

Você considera que o produtivismo acadêmico das universidades brasileiras, para atender aos critérios de qualidade CAPES, tem prejudicado a função crítica e social da universidade, a ciência de longo prazo (utilidade do conhecimento inútil, segundo Flexner), a utilidade do inútil (humanidades, segundo Ordine), a autonomia universitária e liberdade acadêmica do professor $e$ as condições de trabalho e qualidade de vida dos docentes?

João dos Reis da Silva Júnior: Sem dúvida e isto fica claro ao longo de toda a entrevista.

Nessas últimas décadas, as universidades, especialmente as norte-americanas, têm assimilado características das corporações. Que propostas deveriam ser implementadas para preservar os cinco elementos essenciais da universidade: (1) equidade; (2) crescimento profissional; (3) colegialidade (ou seja, administração da dimensão acadêmica pelos docentes); (4) autonomia universitária e liberdade acadêmica do docente); (5) flexibilidade?

João dos Reis da Silva Júnior: Novamente, aqui, volto com meu ceticismo de análise. O Brasil é um país resignado. O Golpe Institucional, e as reformas de Temer que completam o que já estava presente no Plano Real e a população aceitou tudo com movimentos que não tiveram reflexos no que acontecia nos três poderes. O legislativo, o executivo e judiciário brigam entre si para fazer melhor as tarefas num país em que seis pessoas têm capital equivalente ao restante da população. Que esperanças podemos ter? Resta-nos resistir para mantermos nossa condição humana. 


\section{REFERÊNCIAS}

KLÉBIS, Daniela. O modelo de universidade no Brasil ficou muito atrasado, diz criador do plano acadêmico da Federal do ABC. Ensino Superior, 22 jun. 2015. Disponível em: < https://www.revistaensinosuperior.gr.unicamp.br/reportagens/o-modelo-de-universidade-nobrasil-ficou-muito-atrasado-diz-criador-do-plano-academico-da-federal-do-abc>. Acesso em: 02 fev. 2018.

SILVA JÚNIOR, João dos Reis. The new Brazilian university: a busca por resultados comercializáveis[recurso eletrônico]. Bauru: Canal6, 2017. ISBN 978-85-7917-425-4.

\section{Sobre o Entrevistado}

João dos Reis Silva Júnior

E-mail: jr@ufscar.br

Universidade Federal de São Carlos - Brasil

Pós-doutor em Sociologia Política pela Universidade Estadual de Campinas (UNICAMP) 